\title{
Commentary: Transporting the dead back to life: Improving extracorporeal membrane oxygenation care relies on optimization of transport and patient selection
}

\author{
Usman Ahmad, MD, ${ }^{\mathrm{a}}$ Sudhir Krishnan, MD, ${ }^{\mathrm{b}}$ and Kenneth R. McCurry, MD ${ }^{\mathrm{a}}$
}

\footnotetext{
From the ${ }^{\mathrm{a}}$ Department of Cardiothoracic Surgery, Heart and Vascular Institute, and ${ }^{\mathrm{b}}$ Department of Pulmonary Critical Care and Allergy Medicine, Respiratory Institute, Cleveland Clinic, Cleveland, Ohio. Disclosures: Authors have nothing to disclose with regard to commercial support.

Received for publication Dec 17, 2018; accepted for publication Dec 17, 2018; available ahead of print January 29, 2019.

Address for reprints: Usman Ahmad, MD, Department of Cardiothoracic Surgery, Heart and Vascular Institute, Cleveland Clinic, 9500 Euclid Ave, J4-1, Cleveland, OH 44195 (E-mail: ahmadu@ ccf.org).

J Thorac Cardiovasc Surg 2019;157:1707-8 $0022-5223 / \$ 36.00$

Copyright $(2019$ by The American Association for Thoracic Surgery https://doi.org/10.1016/j.jtcvs.2018.12.055
}

Cardiopulmonary failure can be dramatically acute and may require rapid escalation of life support to prevent end organ damage. Escalation beyond conventional mechanical ventilation and pharmacotherapy may require organ replacement therapy in the form of extracorporeal support. Use of extracorporeal membrane oxygenation (ECMO) as a bridge to recovery or organ transplant has become standard practice in hospitals where such facilities are available.

A large number of hospitals in North America and across the world do not perform ECMO routinely. ECMO is not just about inserting cannulae and establishing adequate flow through an oxygenator. The ongoing care of these patients can be quite challenging and is best performed by a dedicated team, preferably at a high-volume center. Disparate access to ECMO has led to establishment of ECMO transport teams that can now initiate ECMO onsite and transport a patient receiving ECMO to a parent hospital.

Several institutions from Australia, Europe, Asia, and North and South America have reported their experience with ECMO transport. ${ }^{1-4}$ Tipograf and colleagues ${ }^{5}$ have provided an update of their outstanding experience over the past decade. There is no question that there can be complications en route; however, with increasing experience ECMO transport is getting safer. A similar report by a group from Karolinska Institutet highlights some of the complications in what is perhaps the world's largest reported experience. ${ }^{1}$ It is clear from the trend that the use of such facilities will continue to increase even over long distances requiring aerial transport. It is also refreshing to see that overall $>60 \%$ of patients transported on ECMO will get discharged from the hospital.

However, placing a patient on ECMO and transporting to carry out further intensive care is a resource-intensive undertaking. An available-to-all approach will dry up the resources and drown ECMO centers in high volume. Like most other high risk-high reward procedures, the key to improving success lies in improving patient selection. It is facilities.

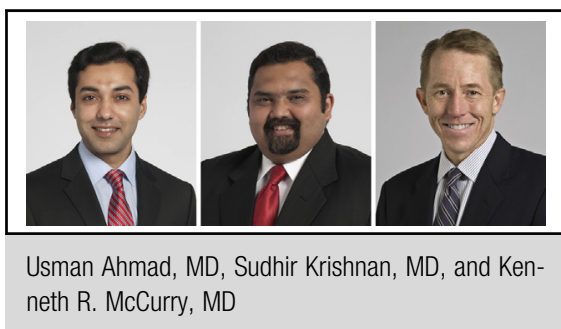

Central Message

Transporting critically ill patients with cardiopulmonary failure on extracorporeal support can be feasible and safely undertaken by experienced teams. Improving selection criteria will allow optimization of resource use.

See Article page 1696.

easy to say that the potential of achieving meaningful organ recovery and quality of life should dictate patient selection for such heroic measures. However, our ability to predict and prognosticate meaningful recovery is still quite poor.

The current inclusion and exclusion guidelines are far from perfect or complete. The complex clinical scenarios requiring ECMO support keep evolving. Ambiguity in predicting outcome can cloud clinical judgment when faced with the time-sensitive question of offering someone lifesaving support. For example, in the past few months our ECMO team has been consulted in the following scenarios. Some of these consults originated from our own hospital services, whereas others were referrals from outside

- 50-year-old man presenting with severe acute respiratory distress syndrome has been in an intensive care unit for more than 1 month, has been receiving venovenous ECMO for more than 3 weeks, has a tracheostomy, a tracheoesophageal fistula, tracheal stent, several necrotic digits, and is extremely malnourished.

- 35-year-old man with a body mass index of 60 with limited mobility and recurrent pneumonia complicated by severe acute respiratory distress syndrome.

- 59-year-old female liver transplant recipient was readmitted from a nursing facility for the third time for aspiration pneumonia. At this aspiration, she has profuse amounts of gastric contents in her airway and is severely hypoxic with maximum ventilator support. 
- 65-year-old man who underwent unilateral pulmonary endarterectomy 2 weeks prior with no relief of pulmonary hypertension now has hemoptysis and bilateral diffuse consolidation resulting in refractory hypoxemia despite conventional therapy; not a lung transplant candidate.

Some of the above-mentioned patients were supported with ECMO and not all of them were discharged alive. Patient selection at best is an imperfect science!

A significant challenge in interpreting the reported retrospective data from various centers is the obvious selection bias. To date there has been sparse characterization of patients who are turned down for ECMO by the evaluating center. In our opinion, optimizing our selection skills requires evaluating the outcomes in not only the patients who were placed on ECMO but also those who were turned down at the time of consultation. Tipograf and colleagues ${ }^{5}$ report that between June 2015 and December 2017 they reviewed 474 referrals out of which only 124 patients $(26 \%)$ were selected for transport with or without ECMO. The answer to better selection lies in evaluating the overall cohort of all referred patients to identify true prognostic criteria. We look forward to future reports from this group that include evaluation of their referral database.

Until there is a common set of evidence-based inclusion and exclusion criteria, every center will need to have its own guidelines that are suited to its resources and logistics. When it comes to saving a human life, heroics will always have a place in our practice. However, heroics need to go hand in hand with medical evidence and social ethics so that they are not misguided.

\section{References}

1. Broman LM, Holzgraefe B, Palmer K, Frenckner B. The Stockholm experience: interhospital transports on extracorporeal membrane oxygenation. Crit Care. 2015; $19: 278$.

2. Austin DE, Burns B, Lowe D, Cartwright B, Clarke A, Dennis M, et al. Retrieval of critically ill adults using extracorporeal membrane oxygenation: the 9-year experience in New South Wales. Anaesth Intensive Care. 2018;46:579-88.

3. Fletcher-Sandersjöö A, Frenckner B, Broman M. A single-center experience of 900 interhospital transports on extracorporeal membrane oxygenation. Ann Thorac Surg. 2019;107:119-27.

4. Mendes PV, de Albuquerque Gallo C, Besen BAMP, Hirota AS, de Oliveira Nardi R, Dos Santos EV, et al. Transportation of patients on extracorporeal membrane oxygenation: a tertiary medical center experience and systematic review of the literature. Ann Intens Care. 2017;7:14.

5. Tipograf Y, Liou P, Oommen R, Agerstrand C, Abrams D, Brodie D, et al. A decade of interfacility extracorporeal membrane oxygenation transport. J Thorac Cardiovasc Surg. 2019;157:1696-706. 